\title{
Concordance analysis for QTL detection in dairy cattle: a case study of leg morphology
}

\author{
Irene van den Berg ${ }^{1,2,3^{*}}$, Sébastien Fritz ${ }^{4}$, Sabrina Rodriguez ${ }^{1,2,5}$, Dominique Rocha ${ }^{1,2}$, Mekki Boussaha ${ }^{1,2}$,
} Mogens S Lund ${ }^{3}$ and Didier Boichard ${ }^{1,2}$

\begin{abstract}
Background: The present availability of sequence data gives new opportunities to narrow down from QTL (quantitative trait locus) regions to causative mutations. Our objective was to decrease the number of candidate causative mutations in a QTL region. For this, a concordance analysis was applied for a leg conformation trait in dairy cattle. Several QTL were detected for which the QTL status (homozygous or heterozygous for the QTL) was inferred for each individual. Subsequently, the inferred QTL status was used in a concordance analysis to reduce the number of candidate mutations.
\end{abstract}

Methods: Twenty QTL for rear leg set side view were mapped using Bayes C. Marker effects estimated during QTL mapping were used to infer the QTL status for each individual. Subsequently, polymorphisms present in the QTL regions were extracted from the whole-genome sequences of 71 Holstein bulls. Only polymorphisms for which the status was concordant with the QTL status were kept as candidate causative mutations.

Results: QTL status could be inferred for 15 of the 20 QTL. The number of concordant polymorphisms differed between QTL and depended on the number of QTL statuses that could be inferred and the linkage disequilibrium in the QTL region. For some QTL, the concordance analysis was efficient and narrowed down to a limited number of candidate mutations located in one or two genes, while for other QTL a large number of genes contained concordant polymorphisms.

Conclusions: For regions for which the concordance analysis could be performed, we were able to reduce the number of candidate mutations. For part of the QTL, the concordant analyses narrowed QTL regions down to a limited number of genes, of which some are known for their role in limb or skeletal development in humans and mice. Mutations in these genes are good candidates for QTN (quantitative trait nucleotides) influencing rear leg set side view.

\section{Background}

A large number of quantitative trait loci (QTL) have been detected since the availability of genetic markers. However, the mutations that underlie such QTL have been identified only in a few cases [1]. Even reasonably fine-mapped QTL regions of around $2 \mathrm{Mb}$ can still contain multiple genes with a large number of potential causative mutations. Thus, the step from QTL to causative mutations remains difficult.

\footnotetext{
* Correspondence: irene.vanderberg@jouy.inra.fr

${ }^{1}$ INRA, UMR1313 Génétique Animale et Biologie Intégrative, 78350

Jouy-en-Josas, France

${ }^{2}$ AgroParisTech, UMR1313 Génétique Animale et Biologie Intégrative, 16 rue Claude Bernard, 75231 Paris 05, France

Full list of author information is available at the end of the article
}

The present availability of whole-genome sequence data provides new opportunities to narrow down QTL regions to causative mutations [2]. One approach to do this is to eliminate a large number of potential candidate mutations by concordance analysis, which compares the QTL status (homozygous or heterozygous) with status of polymorphisms in the QTL region across genotyped individuals. Assuming a single mutation is responsible for a QTL, an animal will be homozygous for this mutation when it is homozygous for the QTL and heterozygous when it is heterozygous for the QTL [3]. Using this principle, Karlsson et al. [4] were able to reduce the number of candidate causative mutations by $37 \%$ for a locus that affects coat colour in dogs. Although quantitative traits are influenced by several mutations rather than a single mutation, 
concordance between a candidate mutation and the QTL genotype can provide evidence when searching for causative mutations. For example, in a study that focused on a QTL for milk yield and composition on chromosome 6 , concordant polymorphisms were found only in the $A B C G 2$ gene [5].

With the increasing availability of sequence data, such a concordance analysis can be done on a larger scale and could be helpful to reduce the often very large number of candidate mutations in a QTL interval. When a concordance analysis is used for all polymorphisms in a QTL region, it is necessary to set a very low probability of concordance by chance to avoid type 1 errors. The probability of concordance by chance decreases with the number of individuals with predicted statuses [3]. QTL statuses can be derived using a granddaughter design [6] but not all sequenced animals will have a sufficient number of progeny to infer QTL status accurately. A method that provides QTL status for all sequenced individuals is therefore desirable.

Rear leg side view (RLSV) is a quantitative trait recorded in dairy cattle that measures the angle of the hock. Large deviations from the average score are associated with a higher culling rate [7]. Although several QTL for RLSV have been detected $[8,9]$, the causative mutations that underlie these QTL are unknown.

In this study, we used RLSV as an example trait to assess the effectiveness of concordance analysis to narrow down from a QTL region to candidate mutations. First, QTL regions were defined, then the QTL status was derived for a large number of individuals and a concordance analysis was performed.

\section{Methods}

\section{QTL mapping}

Genotypes of 3154 Holstein bulls were used for QTL mapping. These bulls were nearly all Holstein artificial insemination bulls born between 1999 and 2004, owned and progeny-tested by the five major French breeding companies. The genotypes were obtained with the Illumina Bovine SNP50 BeadChip ${ }^{\circledR}$ [10] by Labogena. Quality control included: test of cluster quality, which was performed at the genotyping laboratory level; minimum SNP call rate of 99\%; Hardy Weinberg equilibrium $\left(\mathrm{p}<10^{-4}\right)$; minimum call rate of $98 \%$; parentage checking. These tests, as well as imputation and phasing, were performed upstream of this study, in the routine pipeline of genomic selection. After removal of markers with a minor allele frequency below $0.05,39683$ autosomal markers were retained for analysis. For all bulls, deregressed estimated breeding values (EBV) of RLSV were used for QTL mapping. Deregressed EBV were obtained using a procedure similar to [11], except that when computing the weight $w_{i}$, we assumed that $100 \%$ of the genetic variance was explained by the SNPs. This leads to $w_{i}=\frac{\left(1-h^{2}\right) r_{i}^{2}}{h^{2}\left(1-r_{i}^{2}\right)}$, with $r_{i}^{2}$ being the reliability of the EBV of bull $i$ from progeny information only. The expectation of the bull EBV without progeny information is the pedigree index (PI), leading to the following deregressed EBV:

$$
y=P I+\frac{E B V-P I}{r^{2}} .
$$

QTL mapping was done using Bayes C [12], as implemented in the GS3 software [13] according to the following statistical model:

$$
y_{i}=\mu+u_{i}+\sum_{k=1}^{K} z_{i k} a_{k}+e_{i}
$$

where $y_{i}$ is the deregressed EBV for individual $i, \mu$ the overall mean, $u_{i}$ the polygenic breeding value of individual $i, K$ the number of markers, $z_{i k}$ the genotype of individual $i$ for marker $k$, coded 0,1 or 2 depending on the number of copies of the second marker allele, $a_{k}$ the additive effect of marker $k$, and $e_{i}$ the random residual for individual $i$.

All unknown parameters were assigned prior distributions and sampled with a Monte Carlo Markov chain (MCMC) using Gibbs sampling. The MCMC was run for 180000 iterations, with a burn-in of 20000 iterations and a thin interval of 50. The prior used for $a_{k}$ was a mixture distribution that equals:

$$
a_{k} \mid \pi, \sigma_{a}^{2 \sim}\left\{\begin{array}{c}
0 \text { with probability } \pi, \\
N\left(0, \sigma_{a}^{2}\right) \text { with probability }(1-\pi),
\end{array}\right.
$$

where $\sigma_{a}^{2}$ is the common marker variance and the hyper parameter $\pi$ is the prior probability that the effect of marker $k$ is equal to 0 . Variances $\sigma_{u}^{2}, \sigma_{a}^{2}$ and $\sigma_{e}^{2}$ were assigned inverted chi-square distributions with $v=4.2$ degrees of freedom and scale parameter $S^{2}=\frac{\hat{\sigma}^{2}(v-2)}{v}$ where $\hat{\sigma}^{2}$ is the prior value for $\sigma_{u}^{2}, \sigma_{a}^{2}$ or $\sigma_{e}^{2}$. Parameter $\pi$ was fixed at 0.99 , following [14].

To select QTL regions for further analyses, intervals of 40 adjacent markers (corresponding on average to $2.5 \mathrm{Mb}$ ) were ranked based on the sum of their posterior inclusion probabilities $(\Sigma \mathrm{p})$. The posterior inclusion probability of a marker is the proportion of iterations that included the marker in the model. Since our aim was to select the largest QTL rather than all QTL, the 20 intervals with the highest $\Sigma$ p were selected and denoted as QTL. If intervals overlapped, only the interval with the highest $\Sigma \mathrm{p}$ was selected. Linkage disequilibrium (LD) between the markers in the QTL regions was computed using Lewontin's normalised LD measure (D') [15] and estimated with Haploview 4.2 [16].

To see if QTL regions overlapped with QTL regions for other traits, QTL mapping was also performed for the following traits: milk yield, fat yield, protein yield, fat 
content, protein content, somatic cell count, udder depth, rear udder height, fore udder attachment, locomotion, body depth, chest width, milking speed, udder support, rear teat placement, rear leg side view, stature, rump angle, rump width, front teat placement, front teat length, temperament, angularity, rear leg rear view, foot angle, direct calving ease, maternal calving ease, direct stillbirth, maternal stillbirth, interval from calving to first insemination, longevity, and clinical mastitis.

\section{QTL status prediction}

QTL status was determined for all individuals in the QTL mapping analyses. In addition, for 33 bulls not included in the $50 \mathrm{~K}$ QTL mapping dataset, $50 \mathrm{~K}$ genotypes from Eurogenomics [17] were used to infer their QTL status, as described in [14], so that we could include them in the concordance analysis. The procedure to determine the QTL status of an individual is summarised in Figure 1. For each of the selected QTL regions, the marker effects estimated during QTL mapping were used to infer the QTL status as follows. First, genotypes were phased to define haplotypes, using DagPhase [18], while accounting for family structure. For each of the two haplotypes of an individual, a haplotype effect $H$ was estimated based on a summation of estimated marker effects $\hat{a}_{k}$ : $H=\sum k * \hat{a}_{k}$. This was done either for all markers in the QTL region, or for the 10, 20 or 30 adjacent markers with the highest $\sum \mathrm{p}$ in the region. Subsequently, the difference between the estimated effects of the two haplotypes was used to determine if an individual was homozygous or heterozygous: if both haplotypes had similar effects, the individual was homozygous, while if the difference between the two haplotypes was substantially larger than 0 , the individual was heterozygous. Individuals were grouped based on the absolute value of the difference between two estimated haplotype effects using the following posterior around methods (PAM) [19], as implemented in the fpc R-package [20]:

1. $k$ medoids were randomly selected from the data.

2. All non-medoids were assigned to the closest medoid. The costs of configuration when medoid and data point are switched were calculated using Euclidean distance.

3. The configuration with the lowest cost was selected.

4. Steps 2 and 3 were repeated until the medoids remained equal.

The number of clusters $(k)$ was estimated based on the optimum average silhouette [21], using two, three, or four groups. The QTL status of animals in the cluster with the lowest haplotype difference was denoted homozygous, and that of animals in the cluster with the highest difference was denoted heterozygous. If more than two clusters were present, the QTL status of animals in the other clusters was denoted unknown.

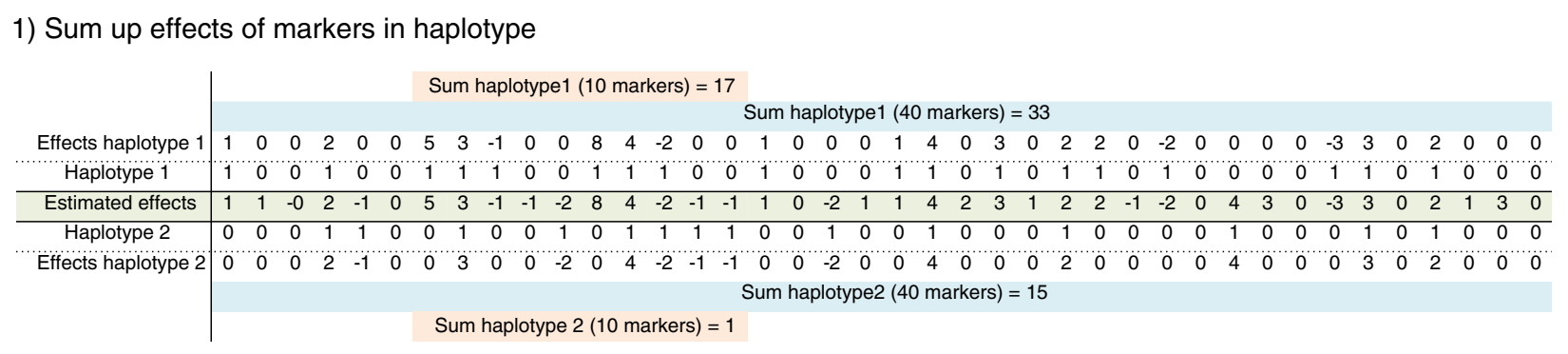

2) Compute difference between the two haplotypes

3) Cluster individuals to determine QTL status

\begin{tabular}{|c|c|c|}
\hline & 40 markers & 10 markers \\
\hline Sum haplotype 1 & 33 & 17 \\
\hline Sum haplotype 2 & 15 & 1 \\
\hline Difference & 18 & 16 \\
\hline
\end{tabular}
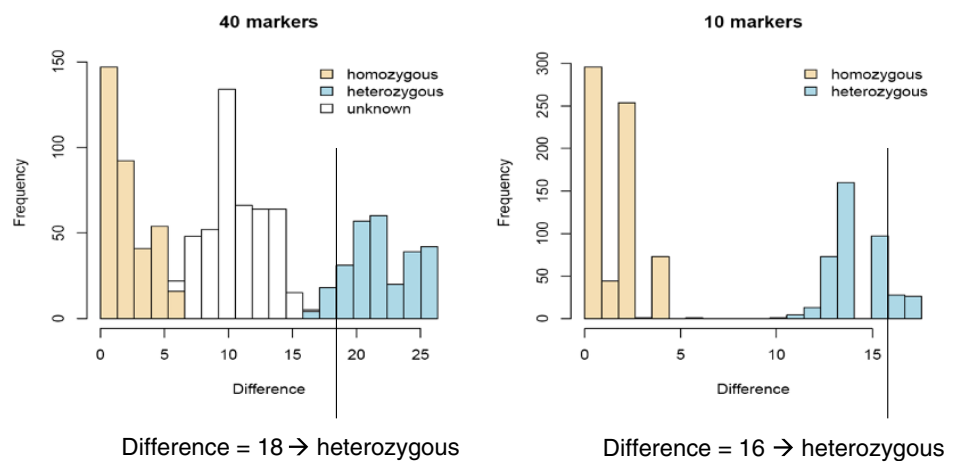

Figure 1 QTL status prediction. 


\section{Concordance analysis}

The concordance analysis compares the estimated QTL status with the genotype of polymorphisms present in the QTL region across individuals. Genotypes of 71 Holstein bulls for polymorphisms detected in the 1000 Bull Genomes project [22] were used for the concordance analysis. For each QTL, a list of polymorphisms present in the QTL region and the corresponding genotypes of the individuals were obtained. Polymorphisms included both SNPs and indels. Regardless of the interval size used for status prediction, the initially detected 40-marker QTL intervals were considered for the concordance analysis. Subsequently, the status of the polymorphisms was compared with the QTL status across individuals. Polymorphisms were only compared with the QTL status of a certain individual if the genotype quality score of the sequence in that individual was equal to 20 or higher. The probability of polymorphisms being concordant by chance was calculated following Ron et al. [3]:

$$
p_{c}=\int_{0}^{1}\left(2[p(1-p)]^{n}[1-2 p(1-p)]^{m} d p\right.
$$

where $p$ is the allele frequency of the reference allele, and $n$ and $m$ the number of heterozygous and homozygous individuals, respectively.

A polymorphism was considered concordant with a QTL if:

1. at least $90 \%$ of the individuals were either homozygous for both the polymorphism and the QTL or heterozygous for both the polymorphism and the QTL,

2. its genotype quality score was equal to 20 or higher for at least five homozygous and five heterozygous individuals,

3. and its probability of concordance by chance $\left(p_{c}\right)$ was lower than 1 divided by the total number of polymorphisms present in the QTL region.

For the concordant polymorphisms, annotations were obtained using the "variant effect predictor" application from Ensembl [23] to generate the functional consequences of polymorphisms.

\section{Results}

\section{QTL mapping}

QTL for RLSV were detected on chromosomes 1, 3, 5, 6, $8,10,11,13,14,15,18,19,23,26,28$, and 29. Figure 2 shows the distribution of $\sum \mathrm{p}$ along the genome and the selected QTL regions. The 20 selected QTL regions with their location and $\Sigma \mathrm{p}$ are in Table 1. The $\Sigma \mathrm{p}$ for the QTL regions ranged from 1.08 to 1.72 when using 40marker intervals. Reducing the size of the interval to 30, 20 or 10 markers changed the order of intervals. When intervals of 30 markers were considered, the four largest QTL remained the same but the ranking of most other QTL changed. With an interval size of 10 markers, the ranking was completely different, with the exception of QTL 3.

\section{Status prediction}

There was a large variation in the distribution of the estimated haplotype differences. When the complete 40marker interval used for QTL mapping was taken into account for QTL status prediction, there was no visible separation between homozygous and heterozygous individuals and thus, it was not possible to predict QTL status accurately for most QTL and individuals. With an interval size of 40 markers, individuals were successfully separated in two distinct groups for only three of the 20 QTL, QTL 11, 15, and 19. For three other QTL, QTL 3, 13 , and 20 , individuals were grouped in more than two groups, thus putting a group with unknown status between the homozygous and heterozygous individuals. Reducing the interval size improved the status derivation: with 10-marker intervals, a separation between homozygous and heterozygous individuals could be observed for most QTL. For half of the QTL, i.e. QTL 4, 6, $9,11,12,14,15,18,19$ and 20 , two clearly separated clusters were obtained, while for QTL 1, 3, 7, 13 and 17, individuals were clustered in more than two groups. However, for QTL 2, 5, 8, 10 and 16, distinguishing between homozygous and heterozygous individuals remained difficult. Therefore, these QTL were not used for subsequent

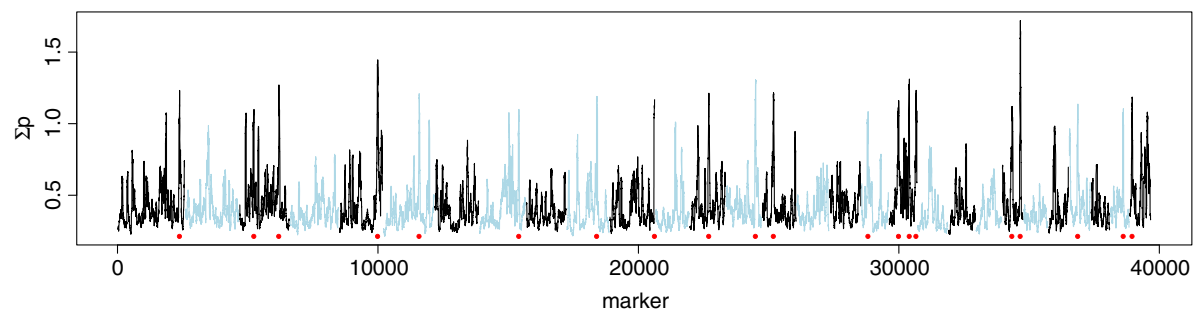

Figure 2 Sum of posterior inclusion probability $(\Sigma \mathbf{p})$ across the genome. Selected QTL are indicated with red dots. 
Table 1 Selected regions and their posterior inclusion probabilities, using different interval sizes

\begin{tabular}{|c|c|c|c|c|c|c|c|c|c|c|c|c|c|}
\hline \multirow[b]{2}{*}{ QTL } & \multicolumn{4}{|c|}{40 markers } & \multicolumn{3}{|c|}{30 markers } & \multicolumn{3}{|c|}{20 markers } & \multicolumn{3}{|c|}{10 markers } \\
\hline & $\mathrm{chr}$ & start & end & $\overline{\Sigma p_{40}}$ & rank & $\Sigma p_{30}$ & $\Sigma p_{30} / \Sigma p_{40}$ & rank & $\Sigma p_{20}$ & $\Sigma p_{20} / \Sigma p_{40}$ & rank & $\Sigma p_{10}$ & $\Sigma p_{10} / \Sigma p_{40}$ \\
\hline 1 & 23 & 46.1 & 48.2 & 1.72 & 1 & 1.55 & 0.90 & 1 & 1.09 & 0.63 & 7 & 0.75 & 0.44 \\
\hline 2 & 5 & 109.6 & 111.7 & 1.45 & 2 & 1.21 & 0.83 & 7 & 0.93 & 0.64 & 24 & 0.57 & 0.39 \\
\hline 3 & 19 & 47.7 & 49.8 & 1.31 & 3 & 1.19 & 0.91 & 2 & 1.02 & 0.78 & 3 & 0.83 & 0.63 \\
\hline 4 & 14 & 66.3 & 69.4 & 1.31 & 4 & 1.15 & 0.88 & 4 & 0.98 & 0.75 & 9 & 0.73 & 0.56 \\
\hline 5 & 3 & 98.6 & 100.7 & 1.27 & 12 & 0.99 & 0.78 & 8 & 0.90 & 0.71 & 15 & 0.62 & 0.49 \\
\hline 6 & 19 & 60.3 & 62.5 & 1.23 & 7 & 1.09 & 0.89 & 18 & 0.79 & 0.64 & 18 & 0.60 & 0.49 \\
\hline 7 & 1 & 146.6 & 148.2 & 1.23 & 15 & 0.97 & 0.79 & 13 & 0.85 & 0.69 & 23 & 0.57 & 0.46 \\
\hline 8 & 15 & 29.5 & 31.3 & 1.22 & 8 & 1.08 & 0.89 & 6 & 0.94 & 0.77 & 35 & 0.50 & 0.41 \\
\hline 9 & 13 & 46.5 & 48.4 & 1.21 & 16 & 0.96 & 0.79 & 31 & 0.67 & 0.55 & 40 & 0.46 & 0.38 \\
\hline 10 & 6 & 87.2 & 90.3 & 1.21 & 10 & 1.01 & 0.83 & 25 & 0.74 & 0.61 & 32 & 0.51 & 0.42 \\
\hline 11 & 10 & 74.9 & 78.2 & 1.19 & 5 & 1.11 & 0.93 & 3 & 1.02 & 0.86 & 1 & 0.85 & 0.71 \\
\hline 12 & 29 & 6.6 & 9.1 & 1.19 & 9 & 1.01 & 0.85 & 9 & 0.90 & 0.76 & 14 & 0.62 & 0.52 \\
\hline 13 & 11 & 104.6 & 107.0 & 1.17 & 6 & 1.09 & 0.93 & 5 & 0.97 & 0.83 & 2 & 0.84 & 0.72 \\
\hline 14 & 19 & 23.9 & 26.0 & 1.16 & 14 & 0.97 & 0.84 & 23 & 0.76 & 0.66 & 19 & 0.59 & 0.51 \\
\hline 15 & 26 & 21.8 & 24.3 & 1.14 & 21 & 0.94 & 0.82 & 17 & 0.81 & 0.71 & 16 & 0.61 & 0.54 \\
\hline 16 & 23 & 24.2 & 27.8 & 1.12 & 23 & 0.93 & 0.83 & 22 & 0.76 & 0.68 & 21 & 0.57 & 0.51 \\
\hline 17 & 28 & 30.8 & 33.9 & 1.10 & 11 & 0.99 & 0.90 & 10 & 0.89 & 0.81 & 4 & 0.78 & 0.71 \\
\hline 18 & 8 & 96.5 & 98.8 & 1.10 & 22 & 0.93 & 0.85 & 28 & 0.71 & 0.65 & 26 & 0.55 & 0.50 \\
\hline 19 & 3 & 40.6 & 43.2 & 1.10 & 20 & 0.95 & 0.86 & 14 & 0.85 & 0.77 & 8 & 0.74 & 0.67 \\
\hline 20 & 18 & 14.0 & 16.8 & 1.08 & 24 & 0.93 & 0.86 & 20 & 0.77 & 0.71 & 12 & 0.63 & 0.58 \\
\hline
\end{tabular}

The 20 QTL with the largest sum of posterior inclusion probabilities $(\Sigma \mathrm{p})$ and their location in $\mathrm{Mb}$, ranked based on their $\Sigma \mathrm{p}$ considering an interval size of 40 markers $(\sim 2.5 \mathrm{Mb})$, and their rank and $\Sigma \mathrm{p}$ if smaller intervals of $30(\sim 1.9 \mathrm{Mb}), 20(\sim 1.3 \mathrm{Mb})$ or $10(\sim 0.6 \mathrm{Mb})$ are used.

concordance analysis. For the QTL with inferred status, the numbers of individuals that were predicted to be homozygous, heterozygous and unknown for the QTL are in Table 2.

Figure 3 shows the status prediction with interval sizes of 10, 20 or 40 adjacent markers for QTL 3, 4, 8 and 11 . For QTL 11, a separation between homozygous and heterozygous individuals was observed with a 40-marker interval. Decreasing the interval size to 20 markers improved the distribution for QTL 3 and 4, and a further decrease to 10 markers resulted in clear separation between homozygous and heterozygous individuals for QTL 4, while for QTL 3, individuals were divided in three groups, homozygous, heterozygous and a middle group with an undetermined status. For QTL 8, no separation was observed, regardless of the interval size. For QTL 3, 4, 8 and 11, Figure 4 shows both the $\sum$ p and the posterior inclusion probability for each SNP. For QTL 11 , there was one major peak in the interval, while several peaks were observed for QTL 3, 4 and 8.

\section{Concordance analysis}

The results of the concordance analysis for the $15 \mathrm{QTL}$ for which status could be inferred are in Table 3. The number of concordant polymorphisms was on average
Table 2 QTL status prediction counts

\begin{tabular}{llllll}
\hline QTL & Homozygous & Heterozygous & Unknown & $\mathbf{n}_{\text {poly }}$ & $\mathbf{p}_{\mathbf{c}}$ \\
\hline 1 & 35 & 6 & 30 & 20486 & $4.28 \times 10^{-24}$ \\
3 & 29 & 15 & 27 & 17365 & $4.70 \times 10^{-23}$ \\
4 & 42 & 29 & 0 & 21333 & $4.28 \times 10^{-35}$ \\
6 & 37 & 34 & 0 & 23499 & $1.95 \times 10^{-33}$ \\
7 & 24 & 29 & 18 & 13858 & $7.86 \times 10^{-24}$ \\
9 & 41 & 30 & 0 & 12124 & $9.06 \times 10^{-35}$ \\
11 & 35 & 36 & 0 & 29105 & $9.66 \times 10^{-33}$ \\
12 & 41 & 30 & 0 & 27411 & $9.06 \times 10^{-35}$ \\
13 & 26 & 20 & 25 & 28541 & $1.25 \times 10^{-22}$ \\
14 & 34 & 37 & 0 & 22154 & $2.20 \times 10^{-32}$ \\
15 & 37 & 34 & 0 & 17454 & $1.95 \times 10^{-33}$ \\
17 & 17 & 20 & 34 & 25321 & $6.30 \times 10^{-17}$ \\
18 & 42 & 29 & 0 & 15746 & $4.28 \times 10^{-35}$ \\
19 & 36 & 35 & 0 & 27747 & $4.32 \times 10^{-33}$ \\
20 & 46 & 25 & 0 & 22771 & $2.22 \times 10^{-36}$
\end{tabular}

For the QTL for which QTL statuses could be inferred, the number of homozygous, heterozygous and unknown individuals, the number of polymorphisms in the QTL region $\left(\mathrm{n}_{\text {poly }}\right)$ and the probability of concordance by chance $\left(p_{c}\right)$. 


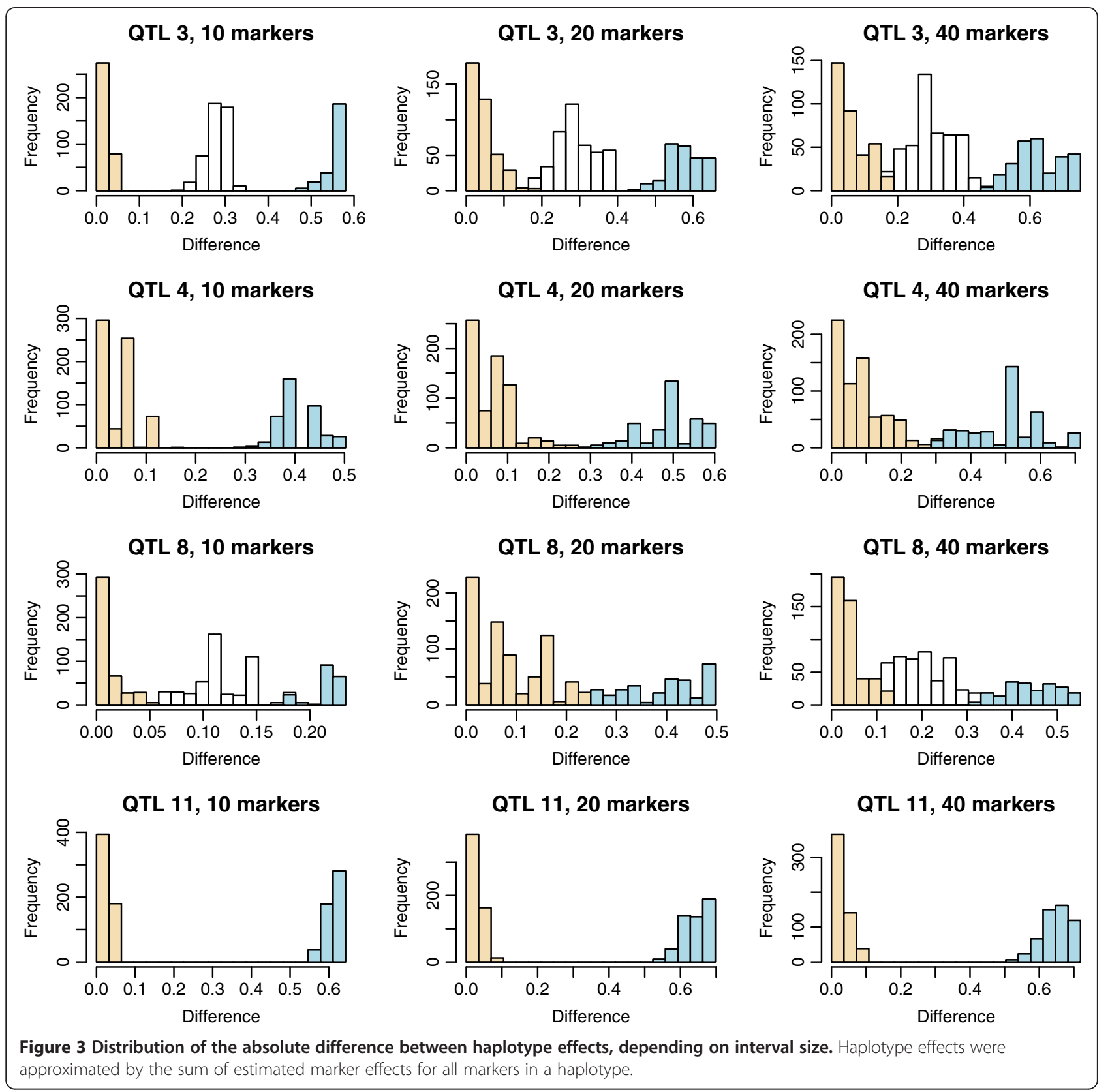

equal to 70 and was generally lower for QTL for which the individuals were clustered in two groups than for QTL with more than two clusters, for which, on average, 202 concordant polymorphisms were found.

Because sequence errors are likely to occur, polymorphisms were considered concordant if they were concordant for at least $90 \%$ of the individuals, rather than setting a $100 \%$ concordance. If a $100 \%$ concordance had been set, the number of concordant polymorphisms would have been substantially reduced. Most QTL had no polymorphisms in complete concordance. Complete concordant polymorphisms were found only for QTL 9, 13, 14, 15 and 18. Figure 5 shows the reduction in the number of concordance polymorphisms when the threshold of allowed errors was reduced from $10 \%$ to $0 \%$ for QTL 3, 4 and 11. For QTL 3, for which the status of some of the animals was set to unknown, the number of concordant polymorphisms was reduced much more than for QTL 4 and 11 for which complete concordance was required. For QTL for which individuals were clustered in two groups, a large proportion of the concordant polymorphisms was still concordant when the error threshold was reduced to $5 \%$, while for QTL for which individuals were clustered in more than two groups, a much lower proportion of polymorphisms remained concordant. 


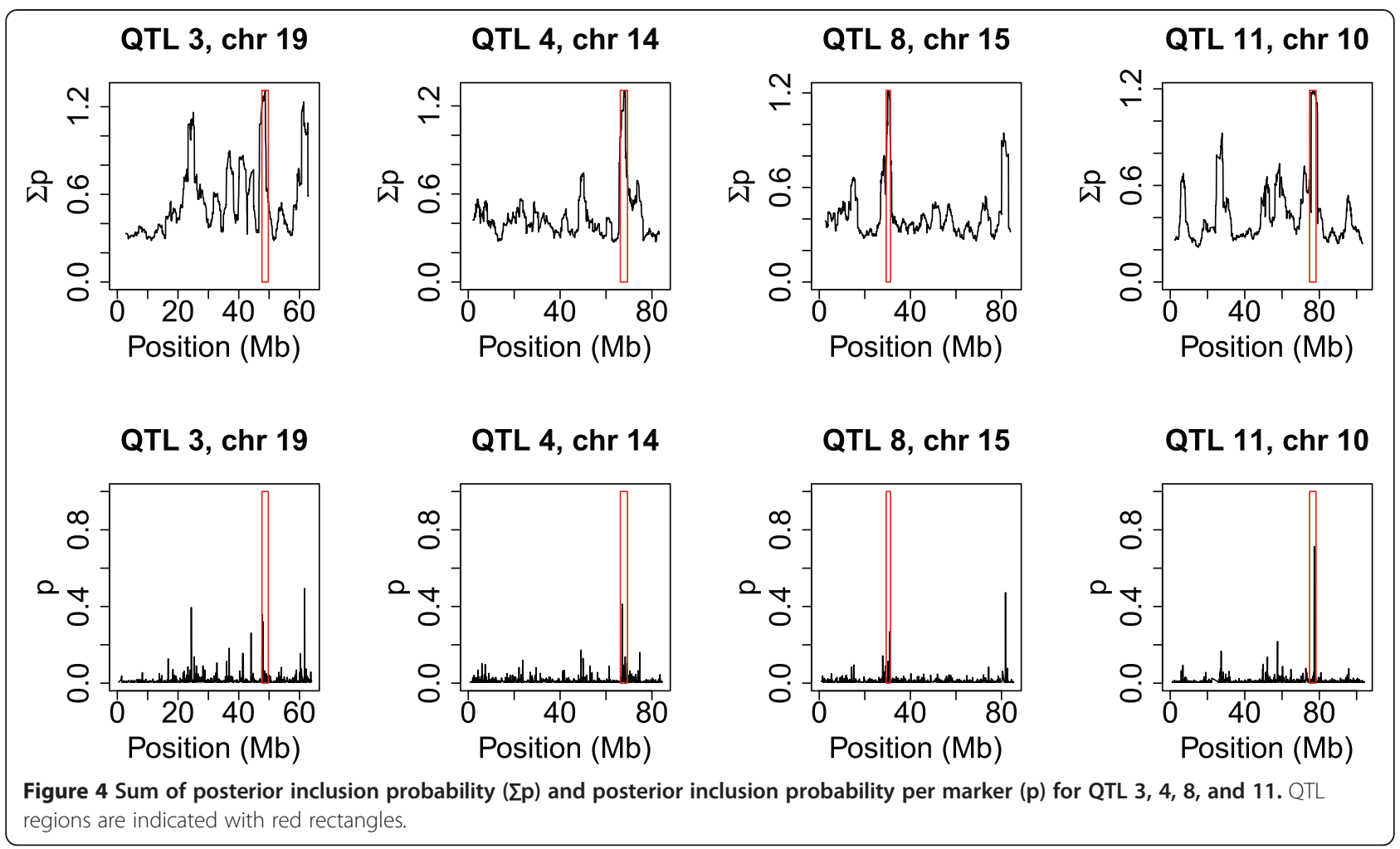

Table 3 Concordant polymorphisms for QTL that were clustered in two or more than two groups

\begin{tabular}{llllllllll}
\hline QTL & indiv & conc & intg & intr & down & up & other & full & genes \\
\hline 2 & groups & & & & & & & & \\
4 & 58 & 42 & 4 & 37 & 0 & 1 & 0 & 0 & VPS13B, OSR2 \\
6 & 64 & 15 & 0 & 12 & 3 & 0 & 0 & 0 & MAP2K6 \\
9 & 59 & 8 & 0 & 7 & 1 & 0 & 0 & 1 & ADARB2, miRNA \\
11 & 65 & 27 & 24 & 0 & 3 & 0 & 0 & 0 & 55 rRNA \\
12 & 43 & 3 & 3 & 0 & 0 & 0 & 0 & 0 & - \\
14 & 58 & 102 & 100 & 0 & 0 & 2 & 0 & 22 & RAP1GAP2 \\
15 & 59 & 340 & 115 & 197 & 0 & 28 & 0 & 6 & BTRC, LBX1 \\
18 & 59 & 63 & 63 & 0 & 0 & 0 & 0 & 1 & - \\
19 & 59 & 35 & 0 & 35 & 0 & 0 & 0 & 0 & COL11A1 \\
20 & 59 & 65 & 65 & 0 & 0 & 0 & 0 & 0 & - \\
\hline$>2$ & groups & & & & & & & & \\
1 & 40 & 327 & 265 & 42 & 4 & 12 & 4 & 0 & SLC35B3, EEF1E1, BLOC1S5, TXNDC5, 5S rRNA, BMP6, U6, DSP, RIOK1, CAGE1, SSR1, RREB1 \\
3 & 37 & 52 & 40 & 8 & 2 & 1 & 1 & 0 & TANC2, ACE3, SCN4A, ICAM2, ERN1, miRNA \\
7 & 46 & 411 & 197 & 126 & 39 & 47 & 2 & 0 & PCBP3, 5S rRNA \\
13 & 34 & 31 & 7 & 21 & 3 & 0 & 0 & 3 & BRD3, EHMT1, ARRDC1, MRPL41, WDR85, PNPLA7, NELF, EXD3 \\
17 & 29 & 187 & 113 & 71 & 3 & 0 & 0 & 97 & KAT6B, KCNMA1, Pseudogene \\
\hline
\end{tabular}

indiv = number of concordant polymorphisms for the QTL used in the concordance analysis, the average number of individuals with known QTL status and sequence quality score $\geq 20$; conc = number of concordant polymorphisms; intg = number of intergenic concordant polymorphisms; intr = number of intronic concordant polymorphisms; down = number of downstream concordant polymorphisms; up = number of upstream concordant polymorphisms; other = number of other concordant polymorphisms including 3' prime variants, synonymous variant, splice variants and non-coding exon variants; full = polymorphisms in complete concordance; and names of the genes containing concordant polymorphisms. 

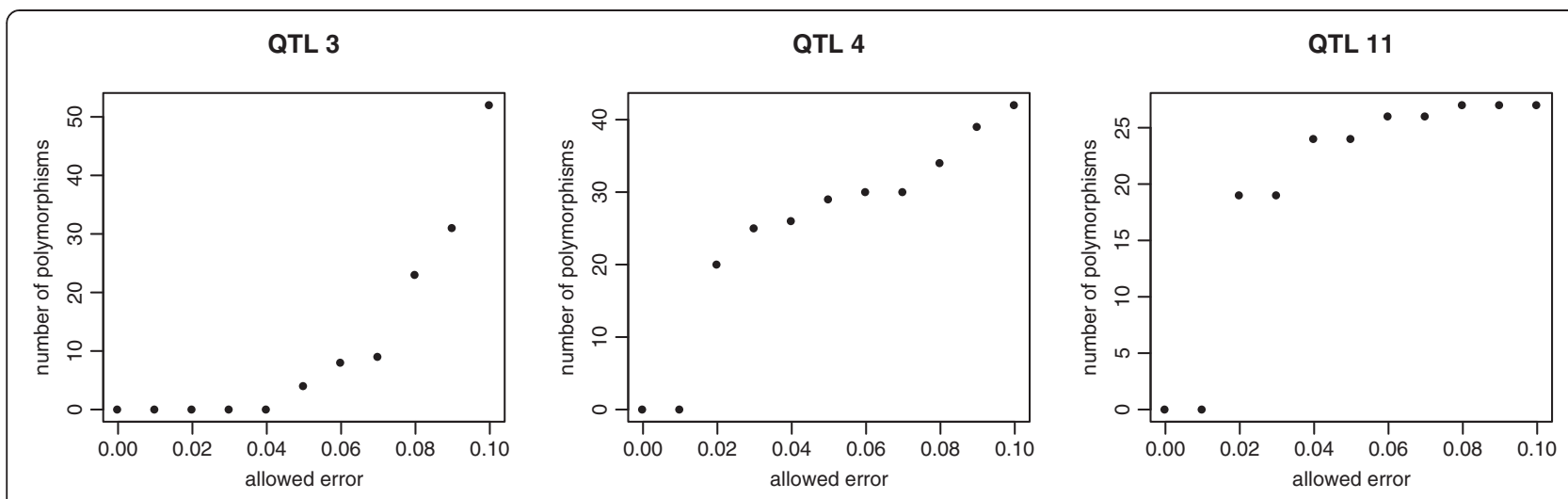

Figure 5 Number of concordant polymorphisms, depending on the accepted proportion of non-concordant individuals.

The number of concordant polymorphisms for the QTL for which individuals were clustered in two groups ranged from 3 for QTL 12 to 340 for QTL 15.

Figure 6 shows LD plots for QTL 9, 11 and 15. The two regions that contained concordant polymorphisms for QTL 9 were in high LD with other regions, but only in complete LD with each other. Concordant polymorphisms for QTL 11 were all located in the same region, which was in low LD with other segments of the QTL region. The two blocks that contained concordant polymorphisms for QTL 15 were in complete LD with each other.

The concordant polymorphisms for QTL for which haplotype effects clustered in two groups, were located in at most two genes, while concordant polymorphisms for QTL for which effects clustered in more than two groups, were generally spread over a larger number of genes.

For QTL 4, 42 polymorphisms were in concordance, of which four were intergenic, 26 were in introns of the $V P S 13 B$ gene, one was in an intron of the OSR2 gene, and one was upstream of this gene. Twelve of the 15 concordant polymorphisms for QTL 6 were intronic variants of the MAP2K6 gene, while the remaining three polymorphisms were located in the downstream region of the same gene. Of the eight concordant polymorphisms found for QTL 9, seven were intronic variants of the $A D A R B 2$ gene and one polymorphism was located downstream of a microRNA gene. For QTL 12, only three intergenic polymorphisms were in concordance with the QTL. The number of comparisons that could be made for two of these variants was limited due to the low quality of the sequence at these positions for most individuals. Almost all of the 102 concordant polymorphisms for QTL 14 were intergenic, except for two polymorphisms located upstream of the RAP1GAP2 gene. For QTL 15, 340 polymorphisms were concordant, of which 115 were intergenic, one was upstream of the $L B X 1$ gene, 197 were in introns of the BTRC gene, and
27 were upstream of this gene. All 63 and 65 concordant polymorphisms for QTL 18 and 20, respectively, were intergenic. The 35 concordant polymorphisms for QTL 19 were all intronic variants of the COL11A1 gene.

The concordant polymorphisms for QTL 1, 3 and 13 were scattered over a large number of genes. QTL 7 had the largest number of concordant polymorphisms, i.e. 441, of which 197 were intergenic, two were in noncoding exons of a 5S rRNA, 39 and 13 were respectively downstream and upstream variants of the same $5 \mathrm{~S}$ rRNA, 196 were in introns of the PCB3 gene, and 34 were upstream variants of this gene. In total, 187 polymorphisms were in concordance with QTL 17. Of these polymorphisms, 113 were intergenic, three were downstream variants of a pseudogene, 65 were intronic variants of the $K A T 6 B$ gene and six were intronic variants of the KCNMA1 gene.

\section{Associations with other traits}

Most of the QTL detected for RLSV also showed peaks in $\sum \mathrm{p}$ for several other traits. Table 4 shows, for each QTL region, the traits that had a $\sum$ p of at least 0.8 . In particular, in the intervals that contained QTL 10 and 15 , peaks in $\Sigma \mathrm{p}$ were observed for a large variety of traits. QTL 15 was, for example, also associated with milk yield, protein yield, fat content, protein content, somatic cell count, udder depth, udder support, angularity, maternal calving ease, longevity, clinical mastitis, and interval from calving to first insemination. Figure 7 shows the association between QTL 15 and several traits.

\section{Discussion}

\section{Concordance analysis}

For 15 of the 20 QTL regions analysed, we were able to strongly reduce the number of candidate mutations by applying concordance analysis. For eight of these QTL, the regions were narrowed down to polymorphisms located in one or two genes. 




Figure 6 Linkage disequilibrium (LD) plots of QTL 9, 11 and 15. LD between markers in the QTL interval was estimated by D'; blocks containing concordant polymorphisms are indicated with black rectangles.

For most of the detected QTL, the distribution of the haplotype differences did not show a clear grouping when all markers in the QTL interval were used to compute the haplotype effects. This was especially the case for the QTL with a larger effect. All 20 QTL had a 5 p larger than $1 . \Sigma \mathrm{p}$ can be larger than 1 because several markers can together explain a QTL, and are thus simultaneously included in the model, or because more than one causative mutation may be present. It is likely that the largest QTL are affected by multiple mutations in the same region rather than by a single mutation. If these mutations have approximately the same effect, the distributions of estimated marker effects will overlap and it is not possible to distinguish between heterozygous individuals with different mutations, which can explain the difficulty in status prediction. When a smaller interval is used to infer the QTL status, fewer mutations will be located in the interval. As a consequence, QTL status could be predicted for a much larger number of QTL when a smaller interval of 10 markers was used. The $\Sigma p$ of these intervals was much lower than the $\Sigma$ p for the complete interval, especially for the QTL for which there were difficulties with status prediction using the complete interval. For example, the highest $\Sigma \mathrm{p}$ was 


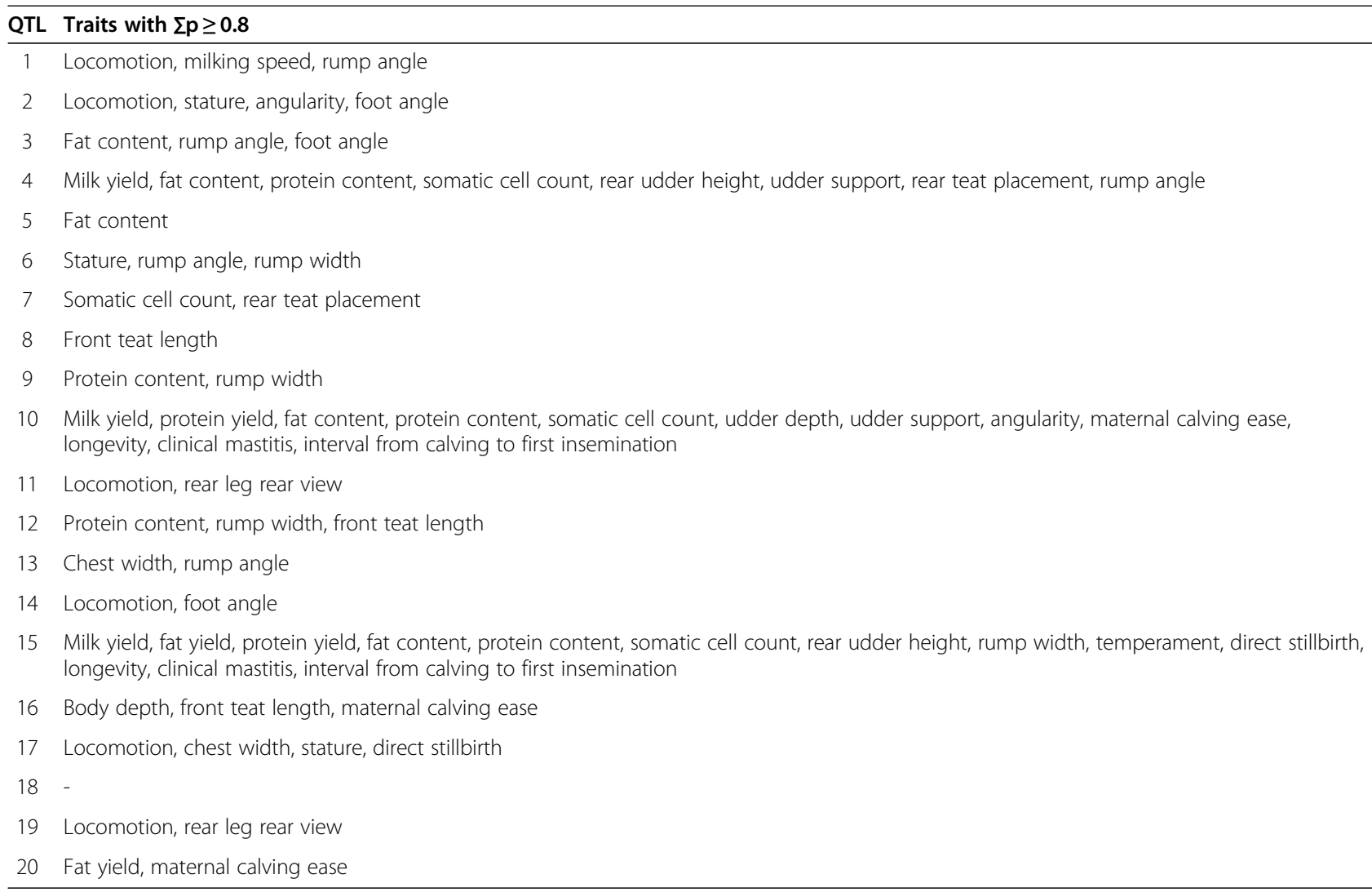

Traits for which the sum of posterior inclusion probabilities ( $\Sigma p)$ in a QTL region equalled at least 0.8 .

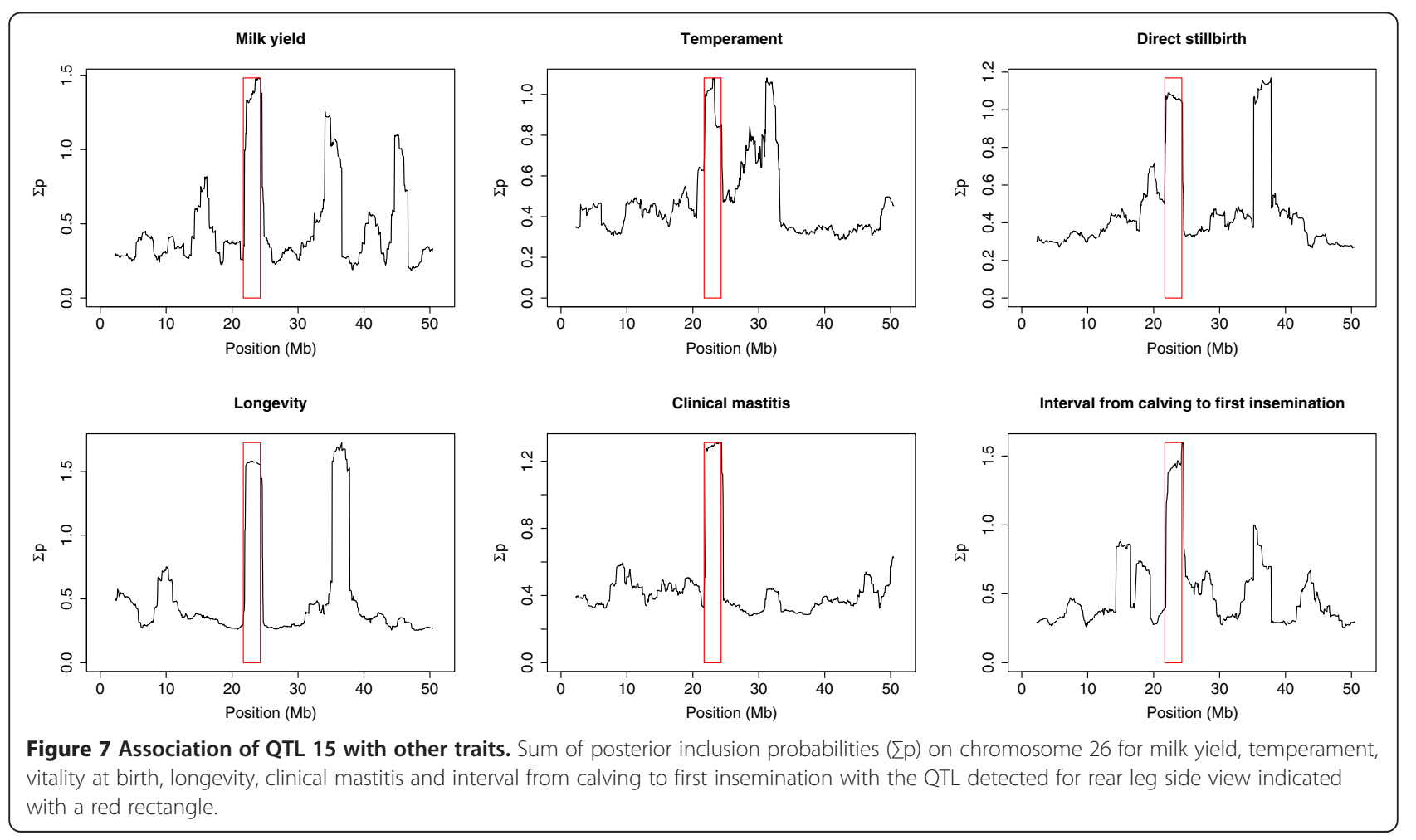


equal to 1.72 when the 40 -marker interval (QTL 1) was used, but dropped to 0.75 when only 10 markers were used. Although using the smaller interval size made it possible to infer the QTL status for a larger proportion of the QTL, this approach may ignore a major part of the QTL by focussing on a single mutation. A more detailed analysis is required to determine whether there are indeed multiple mutations present in these regions and to disentangle their effects. For example, by imputing SNPs to the sequence level for the complete QTL detection design, followed by an association study using the imputed sequences. Specifically, multiple causal variants in a QTL region can be tested using a multiple SNP association model in this region.

Alternatively, it is possible to predict the QTL status of sires using progeny data [6] but this requires data of a sufficiently large number of progeny. For most sires in our dataset, the amount of available data for progeny was not sufficient to accurately derive the QTL status. Thus, it would only be possible to predict the QTL status for a limited number of individuals, which would be too low for a large-scale concordance analysis. Furthermore, if the difficulties in status prediction are indeed due to the presence of multiple QTL in the same interval, then this will cause the same problems in status prediction using the granddaughter design.

Concordance analysis could only be applied for the 15 QTL for which QTL status could be inferred. The number of concordant polymorphisms and the number of genes in which these polymorphisms were located varied widely. For the QTL for which the status could only be accurately inferred for part of the sequenced individuals, the concordant polymorphisms were spread over more genes than for the QTL for which the status could be inferred for all individuals. This shows that a large number of records is necessary to narrow a region down to one or two genes using concordance analysis. Apart from this, the success of concordance analysis also depends on the LD between polymorphisms. Nearby polymorphisms can be in complete LD and, as a consequence, several polymorphisms other than the causative mutation may be concordant with the QTL. The concordance analysis seemed to be able to distinguish between parts of the genome with high levels of LD. For example, the blocks that contained concordant polymorphisms for QTL 15 were in complete LD with each other. Although they were almost in complete LD (99\%) with the blocks in between, concordant polymorphisms were only found in the blocks that were in complete LD with each other. This suggests that with a sufficient number of sequences, concordance analysis can distinguish between polymorphisms that are in high but incomplete LD.

Since both status prediction and sequencing data can contain errors, we allowed for some non-concordant animals. The threshold of allowed non-concordant individuals was set arbitrarily to $10 \%$. When this threshold was reduced, the number of concordant polymorphisms decreased. This decrease was much greater for QTL with more than two clusters than for QTL with two clusters. For the latter QTL, a lower number of comparisons could be made because the QTL status of the middle group was unknown.

\section{Annotations}

Concordant polymorphisms for QTL 4 were intergenic or located in the genes VPS13B and OSR2. In humans, mutations in VPS13B cause the Cohen syndrome, for which symptoms include mental retardation, facial dysmorphism, microcephaly, retinal dystrophy, truncal obesity, joint laxity and intermittent neutropenia [24]. In mice, ORS2 is involved in craniofacial, limb and kidney development [25], palatal growth and patterning [26], and synovial joint formation [27]. Its role in limb development makes it a good candidate gene for RLSV.

All concordant polymorphisms for QTL 6 were located in the MAP2K6 gene, which is expressed in the skeletal muscle, heart, liver and pancreas in mice [28]. In mice, effects attributed to a mutation in this gene include a dwarf phenotype, caused by reduced chondrocyte proliferation, inhibition of hypertrophic chondrocyte differentiation and a delay in the formation of primary and secondary ossification centres [29].

Only eight polymorphisms were concordant with QTL 9, of which one was located downstream of a microRNA and seven were in introns of the ADARB2 gene, an RNA editing gene associated with longevity in both humans and C. elegans [30]. Although RLSV is correlated with longevity in cattle [7] and several of the QTL regions did show peaks in $\Sigma \mathrm{p}$ for longevity, this is not the case for QTL 9.

Concordant polymorphisms for QTL 11 were intergenic, except for three polymorphisms that were located in the downstream region of the 5S rRNA, a part of the ribosome that is required for normal translation in most ribosomes but with no known precise function [31].

For the QTL with two clusters, the largest number of concordant polymorphisms was found for QTL 15, i.e. 340, of which 115 were intergenic variants, 197 were in introns of the $B T R C$ gene, 27 were upstream variants of this gene and one was an upstream variant of the $L B X 1$ gene. In mice, mutations in the BTRC gene are reported to affect spermatogenesis [32], mammary gland development [33], tumorigenesis [33] and retinal development [34]. Both $B T R C$ [35,36] and $L B X 1$ [36] have been associated with split-hand/split-foot malformations in humans. Furthermore, $L B X 1$ is involved in limb development in mice $[37,38]$, thus it is a good candidate gene for a QTL involved in bovine leg conformation. In addition, in mice 
the gene $L B X 1$ is reported to play a role in neural tube development [39], heart development [40], and central respiratory rhythmogenesis [41]. Thus, a wide range of effects have been identified for mutations in these genes in humans and mice. Interestingly, the QTL region detected for RLSV also affected a large number of other traits in dairy cattle, including longevity, confirmation, milk production, clinical mastitis and temperament.

All concordant polymorphisms of QTL 19 were located in introns of the COL11A1 gene. In mice, mutations in COL11A1 result in chondrodysplasia, which is characterized by various skeletal defects [42-44], including a rotated distal portion of the hind limbs [42]. Other reported effects in mice relate to tendon development [45], myocardial morphogenesis, and heart valve development [46]. Furthermore, mutations in the gene COL11A1 have been associated with Marshall [47] and Stickler [48] syndromes in humans, which include skeletal abnormalities. Thus, with skeletal effects in both humans and mice, COL11A1 is a good candidate gene for a QTL involved in RSLV.

For most of the QTL for which the status prediction resulted in more than two clusters, the concordance analysis resulted in concordant polymorphisms in a large number of genes. Only for QTL 7 and 17, did the concordance analysis narrow the regions down to specific genes. Concordant polymorphisms for QTL 7 were either intergenic, or located in a 5S rRNA gene or in the $P C B P 3$ gene. Molecular functions attributed to $P C B P 3$ include DNA binding and RNA binding [49]. For QTL 17 , concordant polymorphisms were intergenic, located in the downstream region of a pseudogene, or intronic variants of the $K A T 6 B$ and $K C N M A 1$ genes. In mice, reduced expression of $K A T 6 B$ results in developmental anomalies of the skeleton and brain [50]. In humans, KAT6B has been associated with Ohdo syndrome for which symptoms include skeletal, facial, cardiac and dental abnormalities [51] and with genitopatellar syndrome [52], a skeletal dysplasia. In mice, mutations in the KCNMA1 gene cause cerebellar dysfunction, abnormal locomotion, and deficient motor coordination [53]. QTL 17 is also associated with locomotion.

Concordant polymorphisms for QTL 1 were present in 12 genes, including 15 intronic variants of the BMP6 gene, which is involved in cartilage and bone formation [54]. Six genes with polymorphisms concordant with QTL 3 were identified. Of these six genes, $S C N 4 A$ is known to cause muscle weakness in mice [55] and humans [56]. The known functions of the eight genes that contained concordant polymorphisms for QTL 13 are not clearly related to RLSV, except for EHMT1, which is associated with Kleefstra syndrome in humans [57]. Although limb abnormalities are not part of the main characteristics of this syndrome, they are present in some patients [57].
Concordant polymorphisms were mainly located in the non-coding regions of the genome. This is also the case for the majority of disease- and trait-associated variants identified in human GWAS and it has been suggested that such non-coding variants are involved in transcriptional regulatory mechanisms [58].

\section{Conclusions}

We were able to perform concordance analysis for 15 of the 20 regions that were most likely to contain QTL for RLSV. For those regions, we could reduce the number of candidate mutations. For some QTL, the concordant analyses narrowed the identified region down to a limited number of genes. Some of these genes are known for their role in limb development, skeletal development in humans and mice, or other effects related to RLSV. Thus, mutations in these genes are good candidates for QTN that affect RLSV.

\section{Competing interests}

The authors declare that they have no competing interests.

\section{Authors' contributions}

$I B, D B, M S L$ and DR designed the study. IB, DB and MSL carried out the study and drafted the manuscript. SF generated and provided phased data. MB and SR generated and provided annotations. All authors read and approved the final manuscript.

\section{Acknowledgements}

IB benefited from an Erasmus-Mundus fellowship and a grant by Apisgene, within the framework of the European Graduate School in Animal Breeding and Genetics. This work was part of the "Rules and Tools" project, financed by the French National Research Agency (ANR-09-GENM-002-01). Most genotype data originated from the Cartofine project funded by ANR and Apisgene, except for the genotypes for 33 bulls used for the status prediction that originated from Eurogenomics. Sequence data originated from the Cartoseq project funded by ANR and Apisgene (ANR10-GENM-0018) and from the 1000 Bull Genomes project. We are grateful to the genotoul bioinformatics platform Toulouse Midi-Pyrenees for providing computing and storage resources.

\section{Author details}

${ }^{1}$ INRA, UMR1313 Génétique Animale et Biologie Intégrative, 78350 Jouy-en-Josas, France. ${ }^{2}$ AgroParisTech, UMR1313 Génétique Animale et Biologie Intégrative, 16 rue Claude Bernard, 75231 Paris 05, France. ${ }^{3}$ Center for Quantitative Genetics and Genomics, Department of Molecular Biology and Genetics, Faculty of Science and Technology, Aarhus University, DK-8830 Tjele, Denmark. ${ }^{4}$ UNCEIA, 149 rue de Bercy, 75012 Paris, France. ${ }^{5}$ INRA

SIGENAE Bioinformatics Team, 31326 Castanet, France.

Received: 23 September 2013 Accepted: 29 April 2014

Published: 19 May 2014

\section{References}

1. Braunschweig MH: Mutations in the bovine $A B C G 2$ and the ovine MSTN gene added to the few quantitative trait nucleotides identified in farm animals: a mini-review. J App/ Genet 2010, 51:289-297.

2. Meuwissen T: Use of whole genome sequence data for QTL mapping and genomic selection. In Proceedings of the 9th World Congress on Genetics Applied to Livestock Production: 1-6 August 2010; Leipzig; 2010 [http://www.kongressband.de/wcgalp2010/assets/pdf/0018.pdf]

3. Ron M, Weller Jl: From QTL to QTN identification in livestock - winning by points rather than knock-out: a review. Anim Genet 2007, 38:429-439.

4. Karlsson EK, Baranowska I, Wade CM, Hillbertz NHS, Zody MC, Anderson N, Biagi TM, Patterson N, Pielberg GR, Kulbokas EJ III, Comstock KE, Keller ET, Mesirov JP, von Euler H, Kämpe O, Hedhammar Å, Lander ES, Andersson G, 
Andersson L, Lindblad-Toh K: Efficient mapping of Mendelian traits in dogs through genome-wide association. Nat Genet 2007, 39:1321-1328.

5. Cohen-Zinder M, Seroussi E, Larkin DM, Loor JJ, Everts-van der Wind A, Lee $J \mathrm{H}$, Drackley JK, Band MR, Hernandez AG, Shani M, Lewin HA, Weller Jl, Ron $\mathrm{M}$ : Identification of a missense mutation in the bovine $A B C G 2$ gene with a major effect on the QTL on chromosome 6 affecting milk yield and composition in Holstein cattle. Genome Res 2005, 15:936-944.

6. Israel C, Weller Jl: Effect of type I error threshold on marker-assisted selection in dairy cattle. Livest Prod Sci 2004, 85:189-199.

7. De Jong G: Scoring legs \& feet in the Dutch conformation scoring system. Interbull Bull 1997, 15:130

8. Ashwell MS, Heyen DW, Sonstegard TS, Van Tassel CP, Da Y, VanRaden PM, Ron M, Weller J, Lewin HA: Detection of quantitative trait loci affecting milk production, health, and reproductive traits in Holstein cattle. J Dairy Sci 2004, 87:468-475.

9. Schrooten C, Bovenhuis H, Coppieters W, van Arendonk JAM: Whole genome scan to detect quantitative trait loci for conformation and functional traits in dairy cattle. J Dairy Sci 2000, 83:795-806.

10. Matukumalli LK, Lawley CT, Schnabel RD, Taylor JF, Allan MF, Heaton MP O'Connel J, Moore SS, Smith TPL, Sonstegard TS, Van Tassel CP: Development and characterization of a high density SNP genotyping assay for cattle. PLoS One 2009, 4:e5350.

11. Garrick DJ, Taylor JF, Fernando RL: Deregressing estimated breeding values and weighting information for genomic regression analyses. Genet Sel Evol 2009, 41:55.

12. Habier D, Fernando RL, Kizilkaya K, Garrick DJ: Extension of the Bayesian alphabet for genomic selection. BMC Bioinformatics 2011, 12:186.

13. Legarra A, Ricard A, Filangi O: GS3, User Manual; 2012 [http://snp.toulouse. inra.fr/ alegarra/manualgs3_last.pdf]

14. van den Berg I, Fritz S, Boichard D: QTL fine mapping with Bayes C(pi): a simulation study. Genet Sel Evol 2013, 45:19.

15. Lewontin RC: The interaction of selection and linkage. I. General considerations; heterotic models. Genetics 1964, 49:49-67.

16. Barrett JC, Fry B, Maller J, Daly MJ: Haploview: analysis and visualization of LD and haplotype maps. Bioinformatics 2005, 21:263-265.

17. Lund MS, de Roos APW, de Vries AG, Druet T, Ducroca V, Fritz S, Guillaume F, Gulbrandtsen B, Liu Z, Reents R, Schrooten C, Seefried F, Su G: A common reference population from four European Holstein populations increases reliability of genomic predictions. Genet Sel Evol 2011, 43:43.

18. Druet T, Georges M: A hidden Markov model combining linkage and linkage disequilibrium information for haplotype reconstruction and quantitative trait locus fine mapping. Genetics 2010, 184:789-798.

19. Kaufman L, Rousseeuw PJ: Finding Groups in Data: An Introduction to Cluster Analysis. Hoboken: John Wiley \& Sons; 2005.

20. Hennig C: fpc: Flexible procedures for clustering, R package version 2.0-3; 2010 [http://CRAN.R-project.org/package $=f p c]$

21. Rousseeuw PJ: Silhouettes: a graphical aid to the interpretation and validation of cluster analysis. J Comp Appl Math 1987, 20:53-65.

22. Daetwyler HD, Capitan A, Pausch H, Stothard P, van Binsbergen R, Brøndum RF, Liao X, Djari A, Rodriguez AC, Grohs C, Jung S, Esquerré D, Bouchez O, Gollnick NS, Rossignol MN, Klopp C, Rocha D, Fritz S, Eggen A, Bowman PJ, Coote D, Chamberlain AJ, VanTassell CP, Hulsegge I, Goddard ME, Guldbrandtsen B, Lund MS, Veerkamp RF, Boichard DA, Fries R, et al: The 1000 bull genomes project. Nat Genet. In press.

23. McLaren W, Pritchard B, Rios D, Chen Y, Flicek P, Cunningham F: Deriving the consequences of genomic variants with the Ensembl API and SNP Effect Predictor. BMC Bioinformatics 2010, 26:2069-2070.

24. Balikova I, Lehesjoki AE, de Ravel TJL, Thienpont B, Chandler KE, Clayton-Smith J, Träskelin AL, Fryns JP, Vermeesch JR: Deletions in the VPS13B (COH1) gene as a cause of Cohen syndrome. Hum Mutat 2009, 30:E845-E854.

25. Lan Y, Kingsley PD, Cho ES, Jiang R: Osr2, a new mouse gene related to Drosophila odd-skipped, exhibits dynamic expression patterns during craniofacial, limb, and kidney development. Mech Dev 2001, 107:175-179

26. Lan Y, Ovitt CE, Cho ES, Maltby KM, Wang Q, Jiang R: Odd-skipped related 2 (Osr2) encodes a key intrinsic regulator of secondary palate growth and morphogenesis. Development 2004, 131:3207-3216.

27. Gao Y, Lan Y, Liu H, Jiang R: The zinc finger transcription factors Osr1 and Osr2 control synovial joint formation. Dev Biol 2011, 352:83-91.

28. Han J, Lee JD, Jiang Y, Li Z, Feng L, Ulevitch RJ: Characterization of the structure and function of a novel MAP kinase kinase (MKK6). J Biol Chem 1996, 271:2886-2891.
29. Zhang R, Murakami S, Coustry F, Wang Y, de Crombrugghe B: Constitutive activation of MKK6 in chondrocytes of transgenic mice inhibits proliferation and delays endochondral bone formation. Proc Natl Acad Sci U S A 2006, 103:365-370

30. Sebastiani P, Montano M, Puca A, Solovieff N, Kojima T, Wang MC, Melista E, Meltzer M, Fischer SEJ, Andersen S, Hartley SH, Sedgewick A, Arai Y, Bergman A, Barzilai N, Terry DF, Riva A, Anselmi CV, Malovini A, Kitamoto A, Sawabe M, Arai T, Yasuyuki G, Steinberg MH, Hirose N, Atzmon G, Ruvkun G, Baldwin CT, Perls TT: RNA editing genes associated with extreme old age in humans and with lifespan in C. elegans. PLoS One 2009, 4:e8210

31. Ciganda M, Williams N: Eukaryotic $5 \mathrm{~S}$ rRNA biogenesis. Wiley Interdiscip Rev RNA 2011, 2:523-533.

32. Guardavaccaro D, Kudo Y, Boulaire J, Barchi M, Busino L, Donzelli M, Margottin-Goguet F, Jackson PK, Yamasaki L, Pagano M: Control of meiotic and mitotic progression by the $F$ box protein $\beta$-Trcp 1 in vivo. Dev Cell 2003, 4:799-812.

33. Kudo Y, Guardavaccaro D, Santamaria PG, Koyama-Nasu R, Latres E, Bronson $\mathrm{R}$, Yamasaki L, Pagano M: Role of F-box protein $\beta$ Trcp1 in mammary gland development and tumorigenesis. Mol Cell Biol 2004, 24:8184-8194.

34. Baquma-Nibasheka M, Kablar B: Abnormal retinal development in the Btrc null mouse. Dev Dyn 2009, 238:2680-2687.

35. de Mollerat XJ, Gurrieri F, Morgan CT, Sangiorgi E, Everman DB, Gaspari P, Amiel J, Bamshad MJ, Lyle R, Blouin JL, Allanson JE, Le Marec B, Wilson M, Braverman NE, Radhakrishna U, Delozier-Blanchet C, Abbott A, Elghouzzi V, Antonarakis S, Stevenson RE, Munnich A, Neri G, Schwartz CE: A genomic rearrangement resulting in a tandem duplication is associated with split hand-split food malformation 3 (SHFM3) at 10q24. Hum Mol Genet 2003, 12:1959-1971

36. Lyle R, Radhakrishna U, Blouin JL, Gagos S, Everman BD, Gehrig C, Delozier-Blanchet C, Solanki JV, Patel UC, Nath SK, Gurrieri F, Neri G, Schwartz CE, Antonarakis SE: Split-hand/split-food malformation 3 (SHFM3) at 10q24, development of rapid diagnostic methods and gene expression from the region. Am J Med Genet 2006, 104A:1384-1395.

37. Schäfer K, Braun T: Early specification of muscle precursor cells by the homeobox gene Lbx1h. Nat Genet 1999, 23:213-216.

38. Watanabe S, Matsushita S, Hayasaka M, Hanaoka K: Generation of a conditional null allele of Lbx1. Genesis 2011, 49:803-810.

39. Krüger M, Schäfer $K$, Braun T: The homeobox containing gene Lbx1 is required for correct dorsal-ventral patterning of the neural tube. J Neurochem 2002, 82:774-782.

40. Schäfer K, Neuhaus P, Kruse J, Braun T: The homeobox gene Lbx 1 specifies a subpopulation of cardiac neural crest necessary for normal heart development. Circ Res 2003, 92:73-80.

41. Pagliardini S, Ren J, Gray PA, VanDunk C, Gross M, Goulding M, Greer JJ: Central respiratory rhythmogenesis is abnormal in $\mathrm{Lbx} 1$ deficient mice. J Neurosci 2008, 28:11030-11041.

42. Seegmiller R, Fraser FC, Sheldon H: A new chondrodystrophic mutant in mice electron microscopy of normal and abnormal chondrogenesis. J Cell Biol 1971, 48:580-593.

43. Li Y, Lacerda DA, Warman ML, Beier DR, Yoshioka H, Ninomiya Y, Oxford JT, Morris NP, Andrikopoulos K, Ramirez F, Wardell BB, Lifferth GD, Teuscher C, Woodward SR, Taylor BA, Seegmiller RE, Olsen BR: A fibrillar collagen gene, Col11a1, is essential for skeletal morphogenesis. Cell 1995 , 80:423-430

44. Fernandes RJ, Weis M, Scott MA, Seegmiller RE, Eyre DR: Collagen XI chain misassembly in cartilage of the chondrodysplasia (cho) mouse. Matrix Biol 2007, 26:597-603.

45. Wenstrup RJ, Smith SM, Florer JB, Zhang G, Beason DP, Seegmiller RE, Soslowsky LJ, Birk DE: Regulation of collagen fibril nucleation and initial fibril assembly involves coordinate interactions with collagens $\mathrm{V}$ and $\mathrm{XI}$ in developing tendon. J Biol Chem 2011, 286:20455-20465.

46. Lincoln J, Florer JB, Deutsch GH, Wenstrup RJ, Yutzey KE: ColVa1 and ColXla1 are required for myocardial morphogenesis and heart valve development. Dev Dyn 2006, 235:3295-3305.

47. Griffith AJ, Sprunger LK, Sirko-Osadsa DA, Tiller GE, Meisler MH, Warman ML: Marshall syndrome associated with a splicing defect at the COL11A1 locus. Am J Hum Genet 1998, 62:816-823.

48. Martin S, Richards AJ, Yates JR, Scott JD, Pope M, Snead MP: Stickler syndrome: further mutations in COL11A1 and evidence for additional locus heterogeneity. Eur J Hum Genet 1999, 7:807-814. 
49. Makeyev AV, Liebhaber SA: Identification of two novel mammalian genes establishes a subfamily of KH-domain RNA-binding proteins. Genomics 2000, 67:301-316.

50. Thomas T, Voss AK, Chowdhury K, Gruss P: Querkopf, a MYST family histone acetyltransferase, is required for normal cerebral cortex development. Development 2000, 127:2537-2548.

51. Clayton-Smith J, O'Sullivan J, Daly S, Bhaskar S, Day R, Anderson B, Voss AK, Thomas T, Biesecker LG, Smith P, Fryer A, Chandler KE, Kerr B, Tassabehji M, Lynch S-A, Krajewska-Wasalek M, McKee S, Smith J, Sweeney E, Mansour S, Mohammed S, Donnai D, Black G: Whole-exome-sequencing identifies mutations in histone acetyltransferase gene KAT6B in individuals with the Say-Barber-Biesecker variant of Ohdo syndrome. Am J Hum Genet 2011, 89:675-681.

52. Campeau PM, Kim JC, Lu JT, Schwartzentruber JA, Abdul-Rahman OA, Schlaubitz S, Murdock DM, Jiang M-M, Lammer EJ, Enns GM, Rhead WJ, Rowland J, Robertson SP, Cormier-Daire V, Bainbridge MN, Yang X-J, Gingras M-C, Gibbs RA, Rosenblatt DS, Majewski J, Lee BH: Mutations in KAT6B, encoding a histone acetyltransferase, cause Genitopatellar syndrome. Am J Hum Genet 2012, 90:282-289.

53. Sausbier M, Hu H, Arntz C, Feil S, Kamm S, Adelsberger H, Sausbier U, Sailer CA, Feil R, Hofmann F, Korth M, Shipston MJ, Knaus HG, Wolfer DP, Pedroarena CM, Storm JF, Ruth P: Cerebellar ataxia and Purkinje cell dysfunction caused by $\mathrm{Ca} 2+$-activated $\mathrm{K}+$ channel deficiency. Proc Natl Acad Sci U S A 2004, 101:9474-9478.

54. Canalis E, Economides AN, Gazzerro E: Bone morphogenetic proteins, their antagonists, and the skeleton. Endocr Rev 2003, 24:218-235.

55. Hayward L, Kim JS, Lee MY, Zhou H, Kim JW, Misra K, Salajegheh M, Wu F, Matsuda C, Reid V, Cros D, Hoffman EP, Renaud JM, Cannon SC, Brown RH: Targeted mutation of mouse skeletal muscle sodium channel produces myotonia and potassium-sensitive weakness. J Clin Invest 2008, 118:1437-1449.

56. Sternberg D, Maisonobe T, Jurkat-Rott K, Nicole $S$, Launay E, Chauveau D, Tabti N, Lehmann-Horn F, Hainque B, Fontaine B: Hypokalaemic periodic paralysis type 2 caused by mutations at codon 672 in the muscle sodium channel gene SCN4A. Brain 2001, 124:1091-1099.

57. Kleefstra T, van Zelst-Stams WA, Nillesen WM, Cormier-Daire V, Houge G, Foulds N, van Dooren M, Willemsen MH, Pfundt R, Turner A, Wilson M, McGaughran J, Rauch A, Zenker M, Adam MP, Innes M, Davies C, López AGM, Casalone R, Weber A, Brueton LA, Navarro AD, Bralo MP, Venselaar $H$, Stegmann SPA, Yntema HG, van Bokhoven H, Brunner HG: Further clinical and molecular delineation of the $9 \mathrm{q}$ subtelomeric deletion syndrome supports a major contribution of EHMT1 haploinsufficiency to the core phenotype. J Med Genet 2009, 46:598-606.

58. Maurano MT, Humbert R, Rynes E, Thurman RE, Haugen E, Wang $H$, Reynolds AP, Sandstrom R, Qu H, Brody J, Shafer A, Neri F, Lee K, Kutyavin T, Stehling-Sun S, Johnson AK, Canfield TK, Giste E, Diegel M, Bates D, Hansen RS, Neph S, Sabo PJ, Heimfeld S, Raubitschek A, Ziegler S, Cotsapas C, Sotoodehnia N, Glass I, Sunyaev SR, et al: Systematic localization of common disease-associated variation in regulatory DNA. Science 2012, 337:1190-1195.

doi:10.1186/1297-9686-46-31

Cite this article as: van den Berg et al:: Concordance analysis for QTL detection in dairy cattle: a case study of leg morphology. Genetics Selection Evolution 2014 46:31.

\section{Submit your next manuscript to BioMed Central and take full advantage of:}

- Convenient online submission

- Thorough peer review

- No space constraints or color figure charges

- Immediate publication on acceptance

- Inclusion in PubMed, CAS, Scopus and Google Scholar

- Research which is freely available for redistribution

Submit your manuscript at www.biomedcentral.com/submit
C Biomed Central 